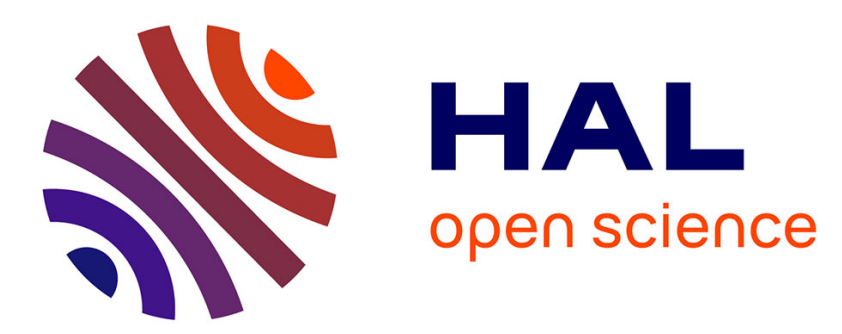

\title{
Nucleation in a Cu-0.8at\%Co alloy. Polarised neutron scattering investigation and clusterdynamics description
}

Th. Ebel, R. Kampmann, R. Wagner

\section{To cite this version:}

Th. Ebel, R. Kampmann, R. Wagner. Nucleation in a Cu-0.8at\%Co alloy. Polarised neutron scattering investigation and clusterdynamics description. Journal de Physique IV Proceedings, 1993, 03 (C8), pp.C8-295-C8-298. 10.1051/jp4:1993858 . jpa-00252289

\section{HAL Id: jpa-00252289 https://hal.science/jpa-00252289}

Submitted on 1 Jan 1993

HAL is a multi-disciplinary open access archive for the deposit and dissemination of scientific research documents, whether they are published or not. The documents may come from teaching and research institutions in France or abroad, or from public or private research centers.
L'archive ouverte pluridisciplinaire HAL, est destinée au dépôt et à la diffusion de documents scientifiques de niveau recherche, publiés ou non, émanant des établissements d'enseignement et de recherche français ou étrangers, des laboratoires publics ou privés. 


\title{
Nucleation in a Cu-0.8at\%Co alloy. Polarised neutron scattering investigation and clusterdynamics description
}

\author{
Th. EBEL, R. KAMPMANN and R. WAGNER \\ Institute for Materials Science, GKSS Research Center, Max-Planck-Strasse, 21502 Geesthacht, Germany
}

\begin{abstract}
By means of polarised small angle neutron scattering it was possible to investigate the nucleation period in a $\mathrm{Cu}-0.8 \mathrm{at} \% \mathrm{Co}$ binary alloy at $490^{\circ} \mathrm{C}$. The experimental data show excellent agreement with a computer simulation based on a recently developed clusterdynamic decomposition model. From these model calculations the time evolution of the cluster size distribution and thus of important decomposition parameters such as nucleation rate and mean radius could be derived. Furthermore, values for the equilibrium solubility, the interfacial energy and the diffusivity were extracted.
\end{abstract}

\section{Introduction}

The investigation of decomposition processes in metallic alloys is of great interest due to many materials properties, which are strongly influenced by the formation of precipitates (e.g. hardness, brittleness and magnetic properties ). Especially the understanding of the basic kinetics during the nucleation period is a very important subject. A quite well suited model system with well-known thermodynamic data is $\mathrm{CuCo}$. In this system nearly pure Co-precipitates are formed during annealing. Most of the former experimental investigations were interpreted in the framework of nucleation, growth and coarsening ( e.g. [1][2][3][4] ). One author, however, proposed on the basis of SANS experiments [5][6] a precursor stage of nucleation in e.g. $\mathrm{Cu}-0.8$ at\% $\mathrm{Co}$ during which rather large areas $(-20 \mathrm{~nm})$ of high Co enrichment $(-7$ at $\%$ ) would be formed. These precursors would lead to an extremely high nucleation rate. It is to point out that due to experimental problems, which are grounded in the smallness of the particles formed during the nucleation period, only the later stages have been investigated properly up to now. Methods of microscopy suffer from the limited size resolution whereas scattering methods have to overcome the low scattering contrast of the small particles. But by means of polarised neutrons it is possible to solve this problem.

\section{Experiment}

The size distribution of a typical CuCo-alloy annealed at a temperature of about $500^{\circ} \mathrm{C}$ for a few minutes causes a small angle scattering contribution which is about one or two orders of magnitude lower than the incoherent scattering of the $\mathrm{Cu}$-matrix. Additionally, background effects such as the $\mathrm{q}^{-4}$-dependent scattering or experimental error sources lead to the impossibility of the detection of the scattering contribution of the particles unless it is possible to subtract the background with great accuracy. A method for background subtraction without using a reference sample can be applied to measurements with polarised neutrons, if one of the alloy components is magnetic as is fulfilled in the case of $\mathrm{CuCo}$. In this case, the superparamagnetism of the small Co-clusters is used for aligning their magnetic moments in a strong external magnetic field. Now, if one assumes no interparticle interaction ( dilute system ) and the similarity of nuclear and magnetic structure of a cluster, the scattering contrast depends in the following way on the spin orientation of the polarised neutrons relative to the magnetic field:

$$
\frac{d \Sigma}{d \Omega} \propto N^{2}+2 \gamma N M+M^{2}
$$

$N$ is the nuclear scattering contribution and $M$ the magnetic part. $\gamma$ can be +1 or -1 depending on the orientation. Thus, if two measurements 
are performed, one with the neutron spin parallel and one with the spin antiparallel to the magnetic field, it is possible to separate the magnetic nuclear interference term by simple subtraction of the two spectra. All non-magnetic contributions to the above mentioned background effects are clearly subtracted and the final spectrum is only caused by the cluster distribution. This separation works without any reference sample, which is a big advantage in comparison to the uncertain subtraction of the signal of the homogenised sample.

The measurements were performed at the SANS-2 facility at GKSS, Geesthacht. A superconducting magnet provided a magnetic field of 4 Tesla at the sample position and a build-in cryostat kept the sample at a temperature of $4.2 \mathrm{~K}$. A Co-Ti-supermirror polariser ( built by $\mathrm{O}$. Schärpf, ILL Grenoble ) was used in connection with a $\pi$-coil spinflipper of the Mezei-type. In addition to the smallangle-detector, a second area-sensitive-detector was used which was swivel-mounted, so it could be moved around the sample. Thus it was possible to cover even large scattering angles up to $135^{\circ}$, which was necessary for the investigation of the scattering contribution of the small particles. In Fig. 1 a typical example is shown for the subtraction of background contributions in the case of the evaluation method used here.

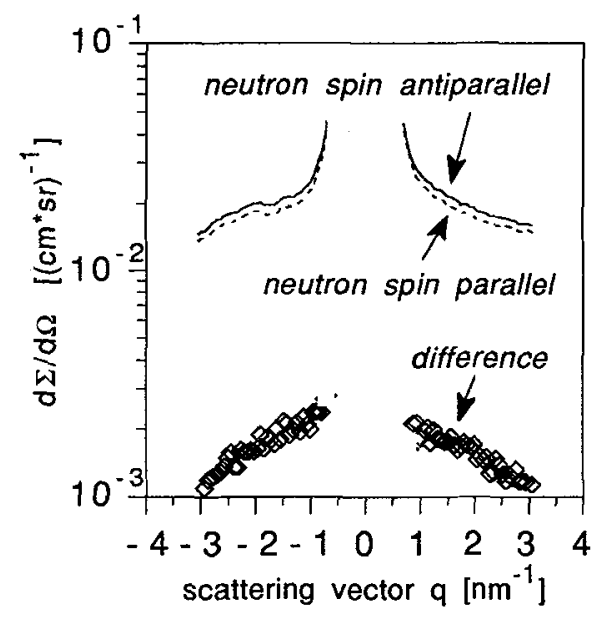

Fig. 1 Example for the subtraction of
background effects.

\section{Clusterdynamic decomposition model}

The clusterdynamic decomposition model was recently developed at GKSS [7][8][9]. By means of this model it is possible to calculate the time evolution of the cluster size distribution in binary alloys where only three input parameters have to be provided: the equilibrium solubility at the regarded temperature, the interfacial energy and the diffusion constant, which only causes a time scaling and has no direct influence on the decomposition process. The whole process is subdivided in small time intervals, in which for every existing cluster size the probabilities for growth resp. shrinkage in this time step are calculated. Depending on these probabilities the percentage of the growing and the shrinking clusters of every cluster size is determined which causes a change in the size distribution. The mentioned probabilities are determined on the basis of the regular solution model. For further information [9] is recommended. With the three input parameters as fit values it is possible to calculate scattering curves from the size distributions yielded and to compare these theoretical spectra with the experimental ones.

\section{Results and discussion}

In fig. 2a-e the experimental results for a $\mathrm{Cu}$ $0.8 \mathrm{at} \% \mathrm{Co}$ alloy at an annealing temperature of $490^{\circ} \mathrm{C}$ are shown. The annealing periods were 3 $\mathrm{min}, 5 \mathrm{~min}, 10 \mathrm{~min}, 15 \mathrm{~min}$ and $30 \mathrm{~min}$. The samples had a diameter of $25 \mathrm{~mm}$ and a thickness of $1.5 \mathrm{~mm}$. They were annealed in a salt bath and rapidly quenched in water. Measurements of the time which was needed for the samples to reach the annealing temperature showed, that it was not sensible to choose time periods smaller than $3 \mathrm{~min}$. In the experiments it turned out that it was not possible to align the magnetic moments of the single Co-atoms completely. Therefore in the case of the 3-min sample it was cooled down to a temperature of $1.8 \mathrm{~K}$. This caused a better alignment of the magnetic moments of the small clusters and thus to a higher scattering signal in comparison to the 5 -min sample. The solid line in each figure is the theoretical scattering curve which results from the cluster size distribution shown in the upper right corner of the figure. All these cluster size distributions result from the same calculation based on the clusterdynamic decomposition model. The three input parameters were:

- equilibrium solubility: $\quad 0.22 \%$

- interfacial energy: $200 \mathrm{mJm}^{-2}$

- diffusion constant: $8.04 \cdot 10^{-16} \mathrm{~cm}^{2} \mathrm{~s}^{-1}$

The use of parameters deviating slightly from these values lead to clearly other theoretical scattering curves. Besides the size distributions, important decomposition parameters such as nucleation rate, mean radius and supersaturation can be extracted from the data, as is shown in fig. 3 and fig. 4 . 

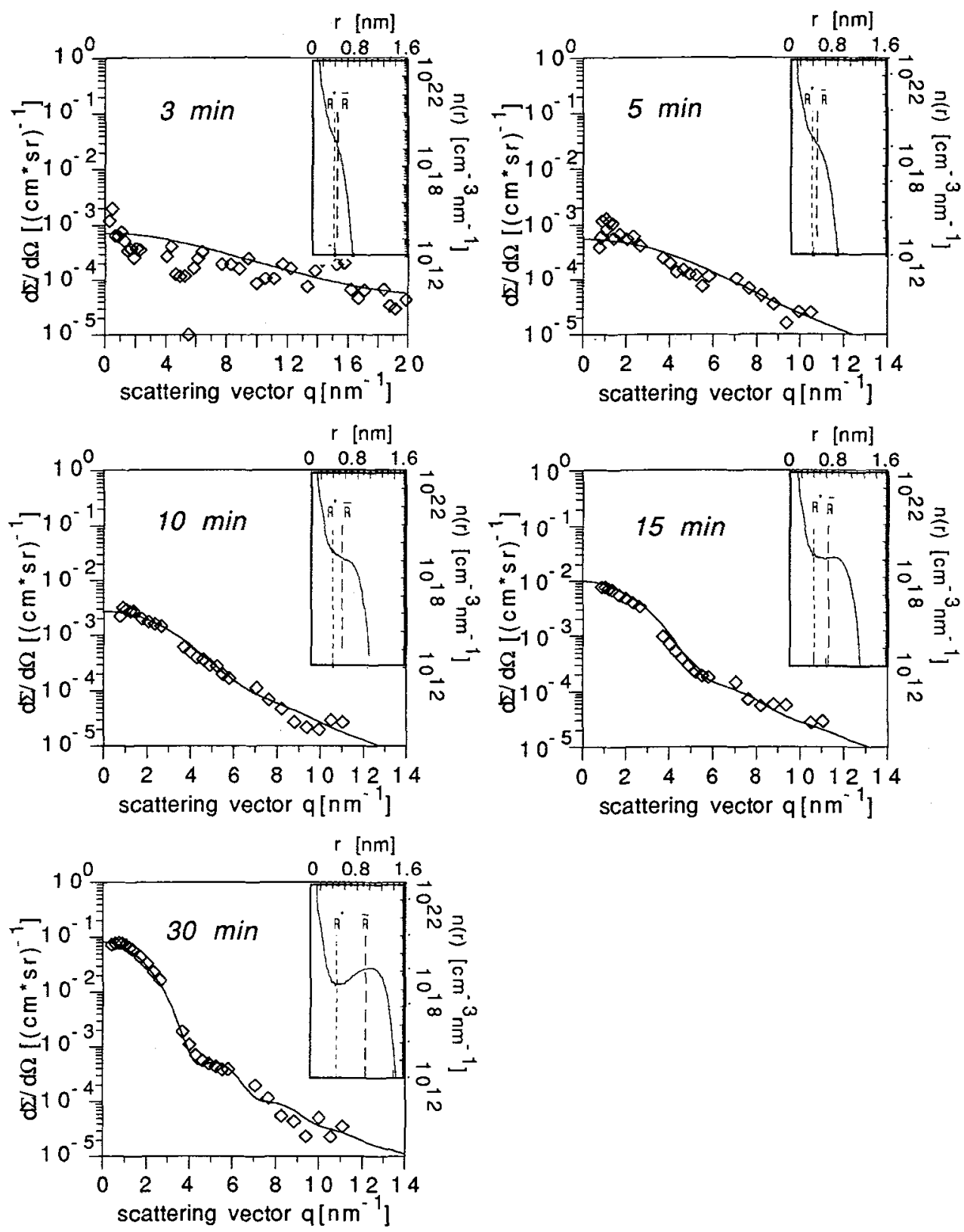

Fig 2a-e Comparison between experimental ( squares) and theoretical ( solid line ) scattering curves. The theoretical curves are calculated from the size distributions in the upper right corner of the figures. All size distributions are determined by the same calculation on the basis of the clusterdynamic ủecomposition model. 


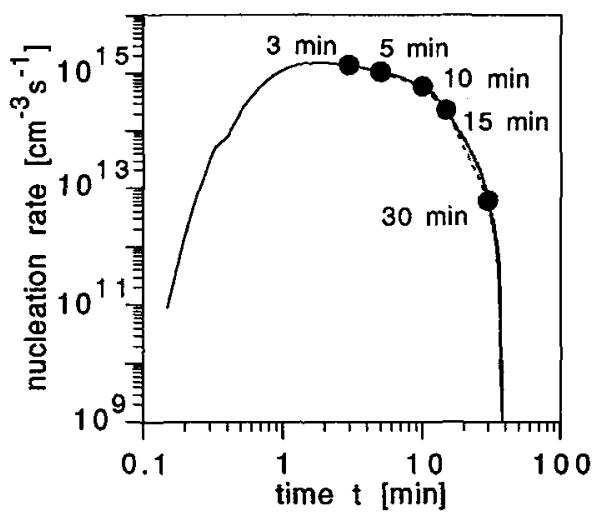

Fig. 3 Calculated time evolution of the nucleation rate.

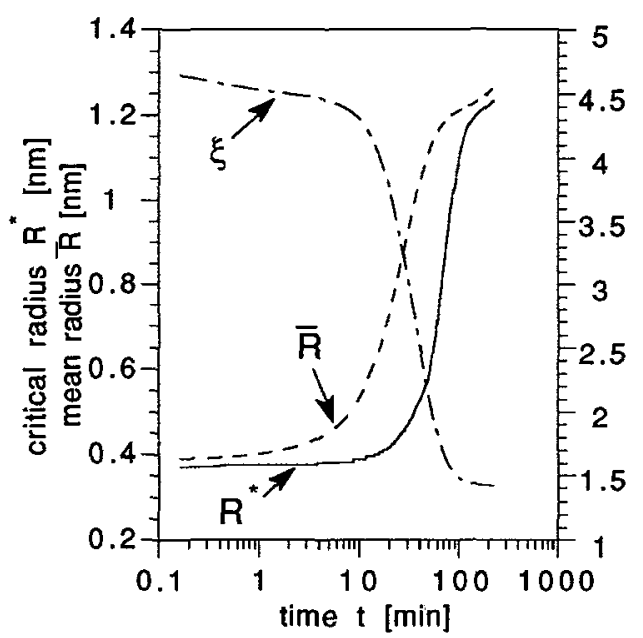

Fig. 4 Calculated time evolution of the mean radius, the critical radius and the supersaturation of the matrix.

\section{Conclusion}

By means of small angle scattering experiments with polarised neutrons it was possible to investigate the nucleation stage in a CuCo-alloy. The high sensitivity of the method used is demonstrated by the detection of the very early stage, where the mean radius of the cluster size distribution yields a value of only about $3.5 \AA$. The experimental data show excellent agreement with a calculation on the base of the clusterdynamic decomposition model. This agreement points to the fact that the nucleation process can be described in a classical way. The values derived for equilibrium solubility, interfacial energy and diffusion constant lie within the range of the former experimental work ( e.g. [3][4] ). The interpretation of the experimental data by means of the clusterdynamic decomposition model leads to the understanding of the kinetics on which the decomposition process is based. No signs of precursor fluctuations were found even at scattering vectors down to $10^{-2} \mathrm{~nm}^{-1}$. However, due to the large $\mathrm{q}^{-4}$-dependent scattering contribution in this region the the interpretation of the scattering data is very difficult and uncertain even in the case of polarised neutron scattering.

\section{References}

[1] F.K. LeGoues and H.I.Aaronson, Acta Met. 28 (1984), 1855

[2] M. Breu, W. Gust, B. Predel, Z.f.Metallkunde, 82 (1991) H.4, 279

[3] B. Frühauf, Ph.D. thesis, University of Stuttgart 1985

[4] R. Hattenhauer, $P h . D$. thesis, University of Göttingen 1992

[5] W. Wagner, Z.f.Metallkunde, 80 (1989) H.12, 873

[6] W. Wagner, Acta metallic mater, 38, no.12 (1990), 2711

[7] M. Haese, diploma thesis, University of Hamburg 1990

[8] Th. Ebel, diploma thesis, University of Hamburg 1989

[9] R. Kampmann, Th. Ebel, M. Haese and R. Wagner, Phys. Stat. Sol.(B), 172, (1992) 295 